\title{
Morphology and Properties of Aminosilane Grafted MWCNT/Polyimide Nanocomposites
}

\author{
Siu-Ming Yuen, ${ }^{1}$ Chen-Chi M. Ma, ${ }^{1}$ Chin-Lung Chiang, ${ }^{2}$ and Chih-Chun Teng ${ }^{1}$ \\ ${ }^{1}$ Department of Chemical Engineering, National Tsing Hua University, Hsinchu 30043, Taiwan \\ ${ }^{2}$ Department of Industrial Safety and Health, Hung Kuang University, Salu, Taichung 443, Taiwan
}

Correspondence should be addressed to Chen-Chi M. Ma, ccma@che.nthu.edu.tw

Received 2 April 2007; Revised 2 September 2007; Accepted 4 October 2007

Recommended by Jun Lou

\begin{abstract}
This investigation presents a novel method for modifying multiwalled carbon nanotubes (MWCNTs). The morphology, electrical resistivity, and percolation threshold of MWCNT/Polyimide nanocomposites were studied. Acid-modified MWCNTs reacted with (3-aminopropyl)triethoxysilane by ionic bonding, and were then mixed with polyamic acid via imidization. TEM microphotographs reveal that silane-grafted MWCNTs were connected to each other. The electrical resistivity of silane-grafted MWCNT/polyimide decreased substantially below than that of acid-treated MWCNTs when the silane-modified MWCNT content was lower than $2.4 \mathrm{wt} \%$. The percolation threshold of the MWCNT/polyimide composites is $1.0 \mathrm{wt} \%$ for silane-modified MWCNT and exceeds $7.0 \mathrm{wt} \%$ for acid-modified MWCNT. The acid-modified MWCNT/polyimide composites possess slightly higher glass transition temperatures than that of pure polyimide. The glass transition temperature of the polyimide increased significantly with silane-modified MWCNT content. Tensile properties of the polyimide have been improved with the MWCNTs content.
\end{abstract}

Copyright (c) 2008 Siu-Ming Yuen et al. This is an open access article distributed under the Creative Commons Attribution License, which permits unrestricted use, distribution, and reproduction in any medium, provided the original work is properly cited.

\section{INTRODUCTION}

Polyimide is a high-performance polymer with high thermal stability, favorable dielectric properties, and chemical resistance. It has been found applications in the microelectronics and composites industries [1]. Carbon nanotubes (CNTs) have attracted much research interest in various areas since their structures were identified in 1991 [2]. They exhibit excellent mechanical and electrical properties, low density, high-surface area, and high chemical resistance [3-8]. CNT/polymer composites are interesting materials whose mechanical properties and electrical conductivity can be improved by the addition of CNT [913]. CNT/polyimide composites are interesting materials and have been extensively studied [14-17]. In our previous investigation, [17] unmodified-, acid-modified-, and amine-modified-MWCNT/polyimide nanocomposites were prepared and their morphology and electrical, thermal, and mechanical properties were examined .

CNT can be modified by refluxing with strong acid or a strong oxidizing agent. Carboxyl and hydroxyl functional groups are formed on the surface of CNTs during acid modification [18]. Acid-modified MWCNT can be modified with silane [19-23]. Shanmugharaj et al. [20] grafted 3-aminopropyltriethoxysilane (APTES) to acid-modified MWCNT and prepared silane-modified MWCNT/natural rubber composites. They suggested that silane can be reacted with the hydroxyl groups $(-\mathrm{OH})$ on the surface of MWCNTs [19-23]. The oxidation of MWCNT may generate carboxylic groups $(-\mathrm{COOH})$ rather than hydroxyl groups. Valentini et al. [23] modified SWCNTs using $\mathrm{CF}_{4}$ plasma to obtain fluorinated SWCNT (f-SWCNT). The f-MWCNT then reacted with APTES and the amine functional group of APTES was grafted on the f-MWCNT. Our previous study has successfully modified MWCNT with silane [24-26]. The silane-modified MWCNTs/Poly (urea urethane) composites have been prepared. The molecular structure and molecular mobility of the carbon-nanotube/PUU nanocomposites have been investigated [26]. These references indicated that carbon nanotube may be dispersed effectively. Increase the dispersion does not improve the electrical conductivity nor decrease the percolation threshold effectively. 
In this study, acid-modified MWCNT was mixed with (3-aminopropyl)triethoxysilane(APTES). Silane functional groups are grafted on the acid-modified MWCNT (APTESMWCNT) by ionic bonding or amide bonding, and some ungrafted APTES may react with polyamic acid to form a complex [1]. After modification of the MWCNT, silane functional groups were remained. The APTES-MWCNT was dispersed in the polyamic acid which was imidized at $300^{\circ} \mathrm{C}$. When the APTES-MWCNT/polyamic acid was heated to $300^{\circ} \mathrm{C}$, the silane reacted on the MWCNT surface, and this reaction was examined. This work studies the electrical resistivity, the percolation threshold, and the thermal properties of the MWCNT/polyimide.

\section{EXPERIMENTAL SECTION}

\subsection{Materials}

Multiwalled carbon nanotubes were obtained from the Nanotech Port Company, Shenzhen, China. The diameters of the MWCNTs were $40-60 \mathrm{~nm}$; their lengths were $0.5-$ $40 \mu \mathrm{m}$, and their special surface areas were $40-3000 \mathrm{~m}^{2} / \mathrm{g}$. Both 4,4' -oxydianiline (ODA) and 3,3',4,4' -benzophenone tetracarboxylic dianhydride (BTDA) were obtained from Chris KEV Company, Inc. Terrance Leawood, KS, USA. (3Aminopropyl)triethoxysilane (APTES) was obtained from Lancaster Synthesis Co., Morecambe, England. N,N-Dimethylacetamide (DMAc) was obtained from Tedia Company Inc., Fairfield, $\mathrm{OH}$, USA.

\subsection{Synthesis of polyamic acid}

The precursor of polyimide (polyamic acid) was prepared by reacting $4,4^{\prime}$-oxydianiline (ODA) with $3,3^{\prime}, 4,4^{\prime}$ benzophenone tetracarboxylic dianhydride (BTDA) in N,NDimethylacetamide (DMAc). The mole ratio of ODA to BTDA was $1: 1.4,4^{\prime}$-Oxydianiline (ODA) was dissolved in DMAc and then $3,3^{\prime}, 4,4^{\prime}$-benzophenone tetracarboxylic dianhydride (BTDA) was added to the $4,4^{\prime}$-oxydianiline (ODA) solution with an ice bath. The polyamic acid was imidized at $300^{\circ} \mathrm{C}$ to yield polyimide (as shown in Scheme 1).

\subsection{Modification of MWCNT}

Pristine MWCNTs were functionalized by refluxing with a mixture of $\mathrm{H}_{2} \mathrm{SO}_{4}$ and $\mathrm{HNO}_{3}$ (weight ratio of $\mathrm{H}_{2} \mathrm{SO}_{4}$ to $\mathrm{HNO}_{3}$ is $3: 2$ ) at $50^{\circ} \mathrm{C}$ for 24 hours. After acid treatment, the MWCNTs were washed using deionized water, filtered and dried at $100^{\circ} \mathrm{C}$. Then, the modified MWCNT was dispersed in DMAc and then (3-aminopropyl)-triethoxysilane (APTES) added to the mixture and was stirred for 1 hour (as presented in Scheme 2). Table 1 presents the mass ratio of APTES to MWCNT. The APTES-treated MWCNT is denoted APTES-MWCNT.

\subsection{Preparation of carbon nanotubes/polyimide nanocomposites}

APTES-MWCNT was added to polyamic acid then put on to a plastic plate and heated to $60^{\circ} \mathrm{C}$ to remove the solvent
TABLE 1: The ratios of APTES to acid-modified MWCNT for APTES-MWCNT.

\begin{tabular}{lc}
\hline ID & APTES : MWCNT (in weight) \\
\hline APTES-MWCNT-1 & $1: 1$ \\
APTES-MWCNT-2 & $2: 1$ \\
APTES-MWCNT-3 & $3: 1$ \\
\hline
\end{tabular}

(DMAc). The mixture was then heated to $300^{\circ} \mathrm{C}$ to produce MWCNT/polyimide composites.

\subsection{Measurement of properties}

\subsubsection{Fourier transform infrared spectroscopy}

The Fourier transform infrared spectroscopy (FT-IR) spectra of unmodified and acid-modified MWCNT were recorded between 800 and $4000 \mathrm{~cm}^{-1}$ using a Nicolet Avatar 320 FTIR spectrometer, from the Nicolet Instrument Corporation, Madison, WI, USA. The sample was dispersed in THF solvent and then coated on $\mathrm{a} \mathrm{CaF}_{2}$ plate and dried in a vacuum oven at $120^{\circ} \mathrm{C}$ before it was tested. The spectra from a minimum of 32 scans were averaged with a signal resolution of $2 \mathrm{~cm}^{-1}$ within the range $400-4000 \mathrm{~cm}^{-1}$.

\subsubsection{X-ray photoelectron spectroscopy (XPS)}

The XPS spectra of MWCNTs were obtained using a ULVACPHI, PHI Quantera with scanning monochromated A1 anode high-resolution X-ray photoelectron spectrometer.

\subsubsection{CP/MAS solid state ${ }^{29}$ Si nuclear magnetic resonance (NMR) spectroscopy}

High-resolution ${ }^{29} \mathrm{Si}$ solid-state NMR was conducted using a Bruker DSX $400 \mathrm{MHz}$ NMR. The samples were ground into fine powder. The ${ }^{29} \mathrm{Si} \mathrm{CP} / \mathrm{MAS}$ NMR spectra of the composites were obtained to characterize the degree of condensation of the APTES-MWCNT/polyimide interpenetrating network with various Multiwalled carbon nanotube contents.

\subsubsection{Morphological properties}

Morphological properties were studied using an FE-SEM (S-4200) scanning electron microscope from Hitachi, Japan, and a JEOL-2000EX transmission electron microscope (TEM) from Japan.

\subsubsection{Measurement of electrical properties}

Surface and volume electrical resistivity were measured using a ULTRA Mesohmeter SM-8220, from the DKK TOA Corporation, Tokyo, Japan. The Surface and volume electrical resistivities of the MWCNT/polyimide composites were measured after various MWCNT contents were added. The charge time was $30 \mathrm{~s}$, and the current voltage of the measurements was $100 \mathrm{~V}$. An average value was obtained from five to six measurements for each sample. 
TABLE 2: Percentages of T and Q substitution of APTES-MWCNT/polyimide composites.

\begin{tabular}{lccc}
\hline $\begin{array}{l}\text { APTES : MWCNT } \\
\text { (in weight) }\end{array}$ & $\begin{array}{c}\text { MWCNT content, } \\
\text { wt\% }\end{array}$ & \% of T substituted & \% of Q substituted \\
\hline $1: 1$ & 0.99 & 97.12 & 2.88 \\
$1: 1$ & 6.98 & 84.02 & 15.98 \\
\hline $2: 2$ & 0.99 & 88.41 & 11.59 \\
$2: 2$ & 6.98 & 86.50 & 13.50 \\
\hline $3: 3$ & 0.99 & 87.27 & 12.73 \\
$3: 3$ & 6.98 & 86.56 & 13.44 \\
\hline
\end{tabular}<smiles>Cc1ccc(C(=O)c2ccc3c(c2)C(=O)OC3=O)cc1C(=O)NC(C)(C)CCCCC(C)(C)C</smiles><smiles></smiles>

Scheme 1: Preparation of the polyimide.

\subsubsection{Glass transition temperature ( $\mathrm{Tg})$}

Glass transition temperatures (Tgs) were measured using a differential scanning calorimeter (DSC) (TA Instruments DSC Q-10). Test data were obtained from $50^{\circ} \mathrm{C}$ to $350^{\circ} \mathrm{C}$ at a heating rate of $10^{\circ} \mathrm{C} / \mathrm{min}$. A minimum of three specimens of each composition were tested.

\subsubsection{Measurements of tensile properties}

Tensile strength test was carried out by using an instron machine model 4488 at room temperature. Test procedure followed the ASTM-D882. Dimensions of test specimens were $50 \mathrm{~mm} \times 5 \mathrm{~mm} \times 0.1 \mathrm{~mm}$. The crosshead speed was $5 \mathrm{~mm} / \mathrm{min}$.

\section{RESULTS AND DISCUSSION}

\subsection{Fourier transfer infrared spectroscopy}

Figure 1(a) shows the FTIR spectrum of unmodified canbon nanotubes; the wavenumbers 3000 and $2800 \mathrm{~cm}^{-1}$ corresponded to $-\mathrm{CH}$ stretching and $1711 \mathrm{~cm}^{-1}$ corresponded to $\mathrm{c}=\mathrm{O}$ stretching. The FTIR result ( $-\mathrm{CH}$ stretching) demonstrates that MWCNTs contain defects, which may be formed during the manufacturing of MWCNT. Figure 1(b) presents the FTIR spectrum of acid-modified carbon nanotubes. The wavenumbers 3000 and $2800 \mathrm{~cm}^{-1}$ corresponded to the stretching of $-\mathrm{CH}$. Carboxylic group stretching $(\mathrm{COOH})$ occurred at $1720 \mathrm{~cm}^{-1}$. Absorption peaks at wavenumbers $1610 \mathrm{~cm}^{-1}$ and $3430 \mathrm{~cm}^{-1}$ correspond to COO- asymmetric stretching and $-\mathrm{COO}-$ stretching, respectively. The FTIR 
TABLE 3: Surface electrical resistivity of MWCNT/polyimide composites.

\begin{tabular}{|c|c|c|c|c|c|}
\hline $\begin{array}{l}\text { MWCNT } \\
\text { content }\end{array}$ & $\begin{array}{l}\text { Surface electrical } \\
\text { resistivity of } \\
\text { unmodified } \\
\text { MWCNT/PI, } \\
\Omega / \mathrm{cm}^{2}\end{array}$ & $\begin{array}{l}\text { Surface electrical } \\
\text { resistivity of } \\
\text { acid-modified } \\
\text { MWCNT/PI, } \\
\Omega / \mathrm{cm}^{2}\end{array}$ & $\begin{array}{l}\text { Surface electrical } \\
\text { resistivity of } \\
\text { APTES- } \\
\text { MWCNT-1/PI, } \\
\Omega / \mathrm{cm}^{2}\end{array}$ & $\begin{array}{l}\text { Surface electrical } \\
\text { resistivity of } \\
\text { APTES- } \\
\text { MWCNT-2/PI, } \\
\Omega / \mathrm{cm}^{2}\end{array}$ & $\begin{array}{l}\text { Surface electrical } \\
\text { resistivity of } \\
\text { APTES- } \\
\text { MWCNT-3/PI, } \\
\Omega / \mathrm{cm}^{2}\end{array}$ \\
\hline 0 & $1.28 \times 10^{15}$ & $1.27 \times 10^{15}$ & $1.27 \times 10^{15}$ & $1.27 \times 10^{15}$ & $1.27 \times 10^{15}$ \\
\hline 0.5 & $6.75 \times 10^{14}$ & $2.99 \times 10^{13}$ & $1.94 \times 10^{15}$ & $2.46 \times 10^{13}$ & $7.88 \times 10^{12}$ \\
\hline 1.0 & $2.03 \times 10^{14}$ & $2.65 \times 10^{13}$ & $2.06 \times 10^{13}$ & $1.70 \times 10^{13}$ & $5.61 \times 10^{12}$ \\
\hline 2.4 & $3.03 \times 10^{12}$ & $2.73 \times 10^{13}$ & $8.07 \times 10^{12}$ & $1.29 \times 10^{13}$ & $5.29 \times 10^{12}$ \\
\hline 4.8 & $8.82 \times 10^{7}$ & $2.31 \times 10^{13}$ & $1.53 \times 10^{12}$ & $2.35 \times 10^{12}$ & $5.58 \times 10^{11}$ \\
\hline 7.0 & $7.59 \times 10^{6}$ & $2.53 \times 10^{13}$ & $8.64 \times 10^{10}$ & $8.58 \times 10^{11}$ & $4.53 \times 10^{11}$ \\
\hline
\end{tabular}
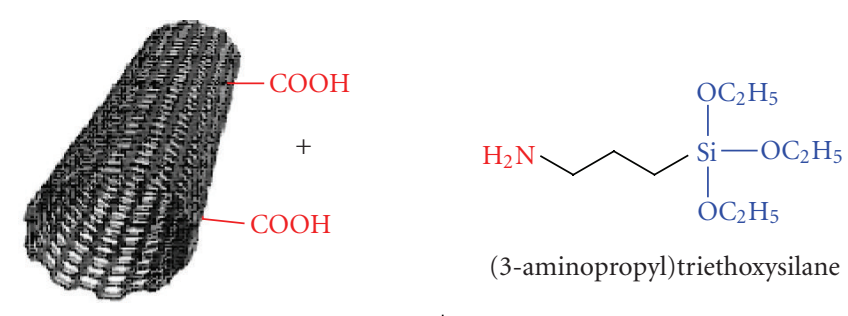

(3-aminopropyl)triethoxysilane

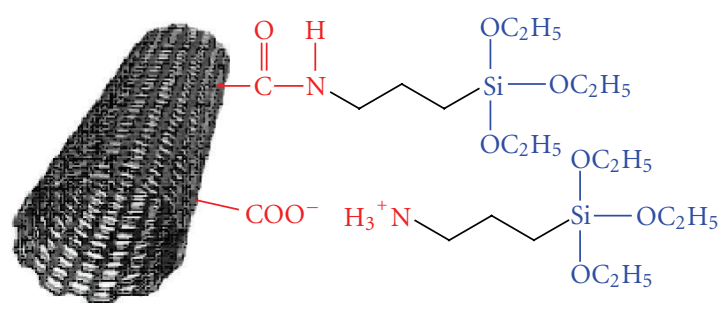

SCHEMe 2: Attachment of APTES with acid-modified MWCNT.

spectrum of acid-modified carbon nanotubes confirmed that pristine MWCNT was modified by $\mathrm{H}_{2} \mathrm{SO}_{4} / \mathrm{HNO}_{3}$ mixed acid generating carboxylic groups. Figure 1(c) presents the FTIR spectrum of the APTES-MWCNT. The wavenumbers at 3000 and $2800 \mathrm{~cm}^{-1}$ corresponded to stretching of $-\mathrm{CH}$. Carboxylic groups stretching $\left(-\mathrm{COO}^{-}\right)$appeared at $1400 \mathrm{~cm}^{-1}$. Stretch of amine salt $(-\mathrm{NH}-)$ appeared at $3100 \mathrm{~cm}^{-1}$. Bend of the amine salt $\left(-\mathrm{NH}_{3}{ }^{+}\right)$appeared at $1610 \mathrm{~cm}^{-1}$ and $1500 \mathrm{~cm}^{-1}$. Absorption peaks at wavenumbers $1110 \mathrm{~cm}^{-1}$ and $956 \mathrm{~cm}^{-1}$ corresponded to $-\mathrm{SiO}-$ stretching. The FTIR spectrum of APTES-MWCNT confirmed that MWCNT was modified with APTES.

\subsection{X-ray photoelectron spectroscopy (XPS)}

Figure 2 presents XPS spectra of the silane-modified MWCNT. Figures 2(a), 2(c), and 2(e) reveal that silane-modified MWCNTs have peaks at about $103 \mathrm{eV}, 154 \mathrm{eV}, 285 \mathrm{eV}, 400 \mathrm{eV}$, and $531 \mathrm{eV}$. The peak appeared at $103 \mathrm{eV}$ was $\mathrm{Si} 2 \mathrm{p}, 154 \mathrm{eV}$ was $\mathrm{Si} 2 \mathrm{~s}, 285 \mathrm{eV}$ was $\mathrm{C} 1 \mathrm{~s}, 400 \mathrm{eV}$ was $\mathrm{N} 1$ s, and $531 \mathrm{eV}$ was O1s, respectively. Figure 2(b) presents the peaks of APTESMWCNT-1 at $400 \mathrm{eV}$, (N1s) can be separated as $400.0 \mathrm{eV}$, $401.4 \mathrm{eV}$, and $402.6 \mathrm{eV}$. The peak at $400.0 \mathrm{eV}$ was amide and peaks at $401.4 \mathrm{eV}$, and $402.6 \mathrm{eV}$ were amino ions. The ratio of $400.0 \mathrm{eV}: 401.4 \mathrm{eV}: 402.6 \mathrm{eV}$ was $1: 0.26: 0.06$. Figures 2(d) and 2(f) present the peaks of APTES-MWCNT2 and APTES-MWCNT-3 at $400 \mathrm{eV}$, (N1s) can be separated as $400.0 \mathrm{eV}$ and $401.4 \mathrm{eV}$. The ratio of $400.0 \mathrm{eV}: 401.4 \mathrm{eV}$ of APTES-MWCNT-2 and APTES-MWCNT-3 were $1: 0.08$ and $1: 0.13$, respectively. The XPS data confirm the most of the silane bonding with the acid-modified MWCNT with amide functional groups and some of them bonded with amino ion.

\subsection{CP/MAS solid state ${ }^{29}$ Si nuclear magnetic resonance (NMR) spectroscopy}

Figures 3(a) to 3(f) present the ${ }^{29} \mathrm{Si}$ solid-state NMR spectra of APTES-MWCNT/polyimide composites. They reveal that trisubstituted siloxane bonds (chemical shift of $\mathrm{T}^{2}, \delta-$ $59.84 \mathrm{ppm}$, and $\mathrm{T}^{3}, \delta-67.002 \mathrm{ppm}$ ) [27] and some tetrasubstituted siloxane bonds (associated with chemical shifts $\mathrm{Q}^{2}$, $\mathrm{Q}^{3}$ and $\mathrm{Q}^{4}$ of $-91,-101$ and $-109.13 \mathrm{ppm}$, resp.) [27] are present in APTES-MWCNT/polyimide composites. Trisubstituted siloxane bonds are defined as a silicon atom possesses four bonds, three of them are bonded with three oxygen atoms and the fourth bond may be bonded with another 


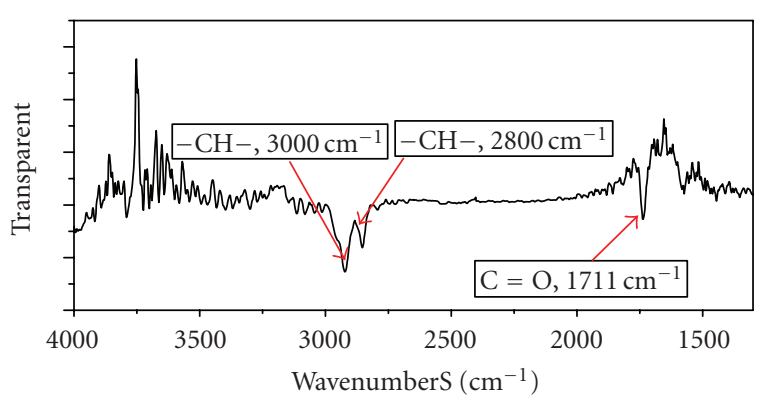

(a)

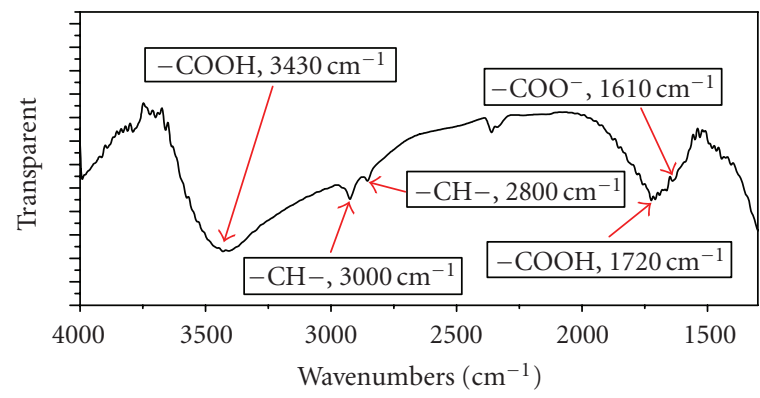

(b)

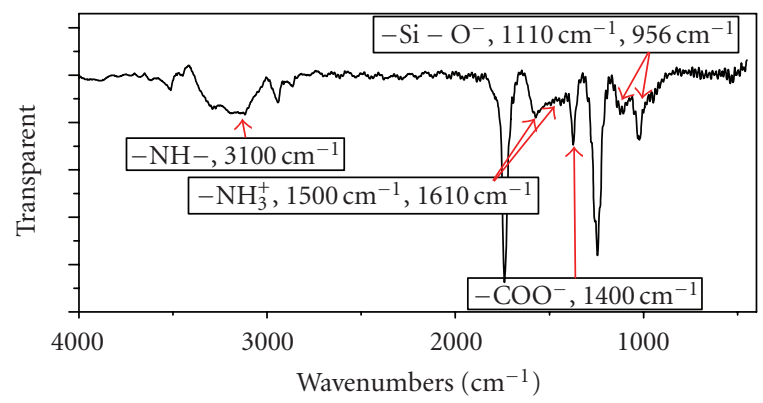

(c)

FIGURE 1: FTIR spectra of (a) unmodified MWCNT, (b) acid modified MWCNT, (c) APTES-MWCNT.

atom, such as carbon atom (Figure 4(a)). Tetrasubstituted siloxane bonds are the four bonds of the silicon atom bonded to oxygen atoms (Figure 4(b)).

Table 2 summarizes the percentages of T and Q substitution of the composites. The tetrasubstituted bond may have been formed when the composites were heated to $300^{\circ} \mathrm{C}$ and the $\mathrm{Si}-\mathrm{C}$ bonds of the APTES may have been broken. When the MWCNT content was low $(1.0 \mathrm{wt} \%)$, the percentage of Q-substitution was proportional to the ratio of APTES to MWCNT. When the ratio of APTES to MWCNT was excessive, most APTES do not graft on the MWCNT. The ungrafted APTES may be responsible for a lower thermal stability, since the $\mathrm{Si}-\mathrm{C}$ bond of the ungrafted APTES is weak. Hence, the proportion of tetrasubstitution increased with the ratio of APTES to MWCNT. When the MWCNT content was high $(7.0 \mathrm{wt} \%)$, the percentage of Q-substitution decreased as the ratio of APTES to MWCNT increased. When the MWCNT content and the silane content were both high, the $\mathrm{SiO}_{\mathrm{x}}$ network was easily formed. APTES grafted on the SiOx network and increased the thermal stability.
Regarding T substitution (Figure 4), the peak height of $\mathrm{T}^{3}$ of the sample with higher MWCNT content was higher than that with a lower MWCNT content. When the APTESMWCNT content was low, since the silane in the nanocomposites could not easily react with the other silane because the APTES-MWCNT intermolecular distance was very large, the interpenetrating network could not easily be formed. However, when the APTES-MWCNT content was high, the silane more easily reacted with the other silane, because the ATPESMWCNT intermolecular distance was shortened.

\subsection{Morphology of MWCNT/polyimide composites}

Figures 5(a)-5(f) present SEM microphotographs of the APTES-MWCNT/polyimide composites. The MWCNT was dispersed in the polymer matrix. Most of the MWCNTs were embedded in the polyimide matrix. Figures 5(a) and 5(b) show SEM microphotographs of the APTES-MWCNT1/polyimide composites. Most APTES-MWCNT were embedded in the polyimide matrix and only a few were pulled out from the matrix. Figures 5(c) and 5(d) indicate that most of the MWCNTs in APTES-MWCNT-2/polyimide composites were embedded in the polyimide matrix and some of the MWCNTs were pulled out from the matrix. Figures 5(e) and 5(f) reveal that most of the MWCNT in APTES-MWCNT2/polyimide composites were also embedded. However, it can be seen that more MWCNTs were pulled out than those of the APTES-MWCNT-1/polyimide composites and APTES-MWCNT-2/polyimide composites. The imprint of the MWCNT on the polyimide matrix (indicated by the arrow in Figure 5(f)) was observed.

Figures 6(a) to 6(f) display the TEM microphotographs of the ATPES-MWCNT/polyimide composites. Figures 6(a) and $6(\mathrm{~b})$ present the TEM microphotographs of the APTES-MWCNT-1/polyimide composites. The MWCNTs were coated with $\mathrm{SiO}_{\mathrm{x}}$ layers, which looked like "needles" and were dispersed in the polymer matrix. Some of the MWCNTs were connected to each other. Some of the $\mathrm{SiO}_{\mathrm{x}}$ was not coated on the MWCNT surface and was aggregated in the shape of cotton balls.

Figures 6(c) and 6(d) show the TEM microphotographs of the APTES-MWCNT-2/polyimide composites. The MWCNTs were also coated with $\mathrm{SiO}_{\mathrm{x}}$ layers and dispersed in the polymer matrix. Some of the MWCNTs were also connected to each other. The MWCNTs were assembled in an " $\mathrm{H}$ " shape or a " $\Psi$ " shape.

Figures 6(e) and 6(f) display TEM microphotographs of the APTES-MWCNT-3/polyimide composites. The $\mathrm{SiO}_{\mathrm{x}}$ was aggregated on the MWCNT surface. Figure 6(e) reveals that the MWCNTs were assembled in the shapes of longer needles which differed from those in Figures 6(a), 6(b). The "needle-shaped" MWCNTs in Figures 6(e), 6(f) were longer and thinner than those in Figures 6(a), 6(b). Figure 6(f) shows that some of the MWCNT have been connected. When the ratio of APTES to MWCNT was high, most of the APTES were not grafted on the surface of acid-modified MWCNTs. Some of the APTES reacted with the polyamaric acid to form a complex [1, 28]. The ungrafted APTES bonded with the grafted APTES, and could 


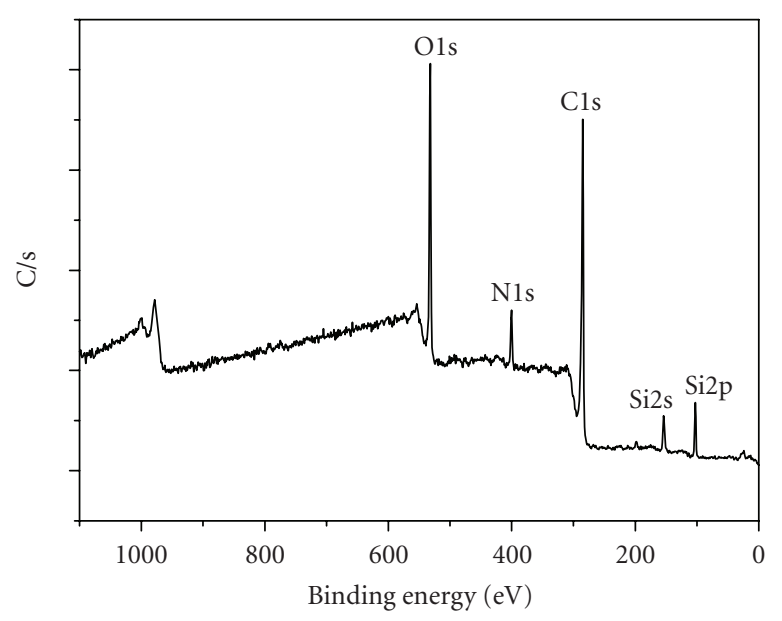

(a)

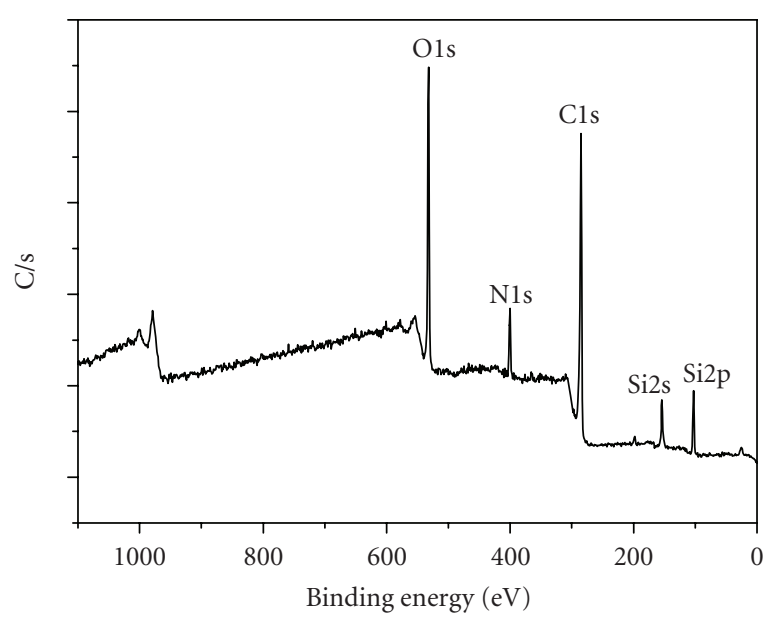

(c)

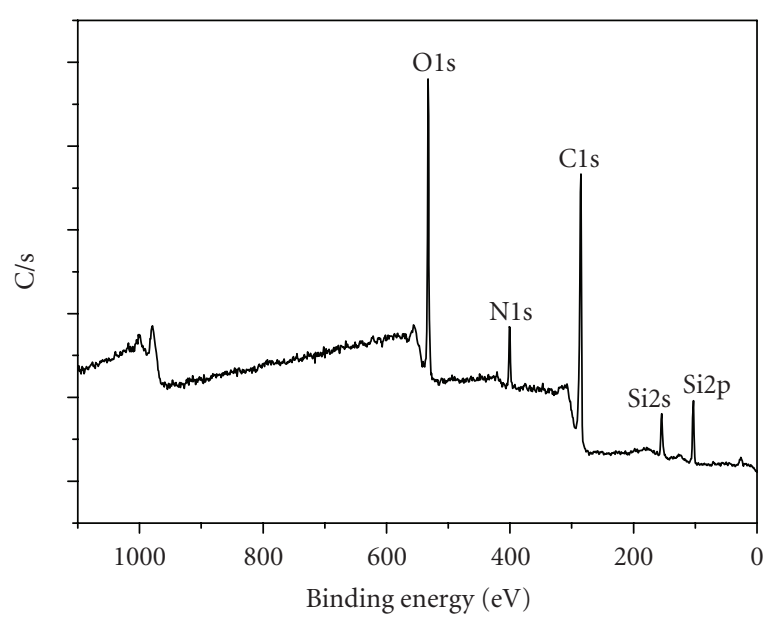

(e)

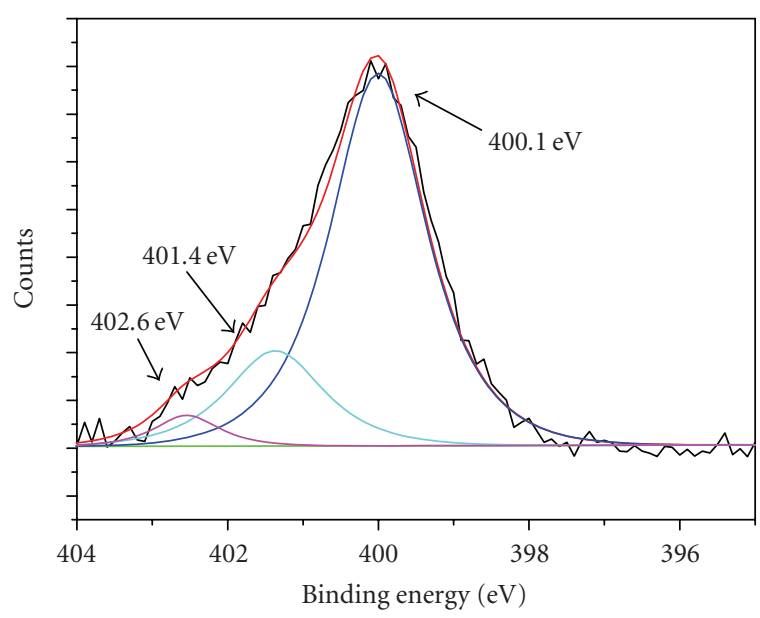

(b)

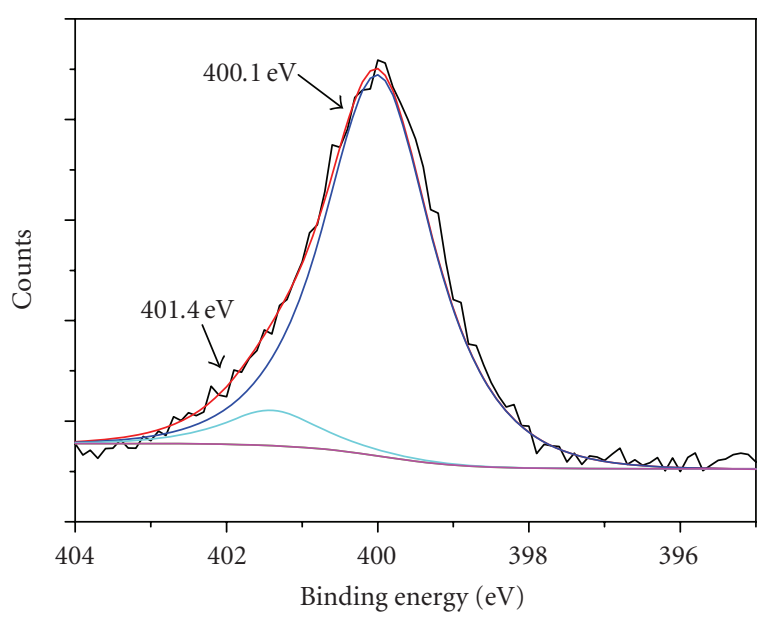

(d)

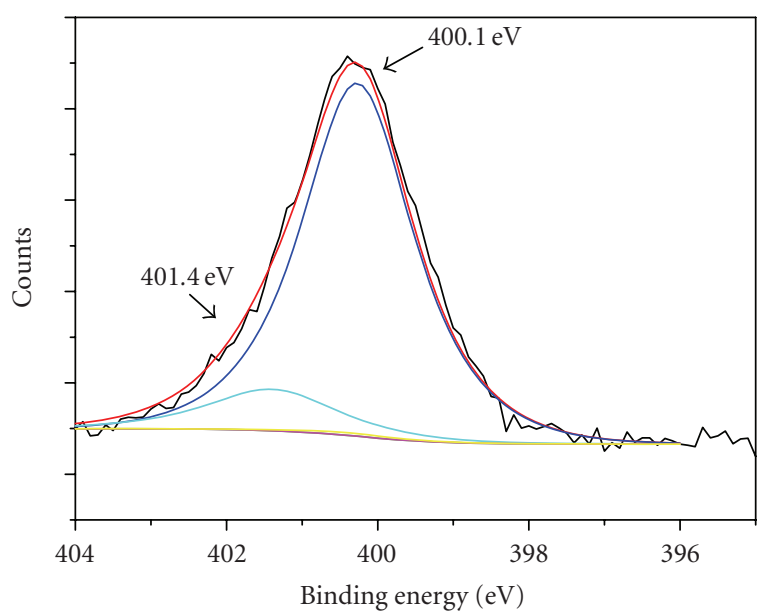

(f)

Figure 2: X-ray photoelectron spectroscopy (XPS) spectra of (a, b) APTES-MWCNT-1, (c, d) APTES-MWCNT-2, and (e, f) APTESMWCNT-3. 


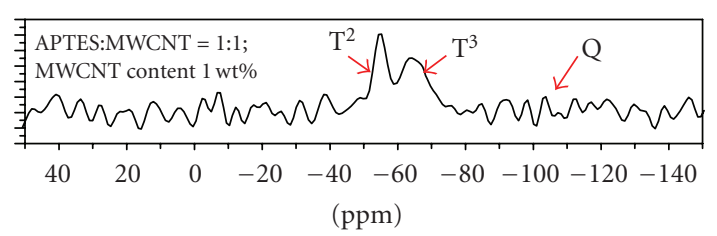

(a)

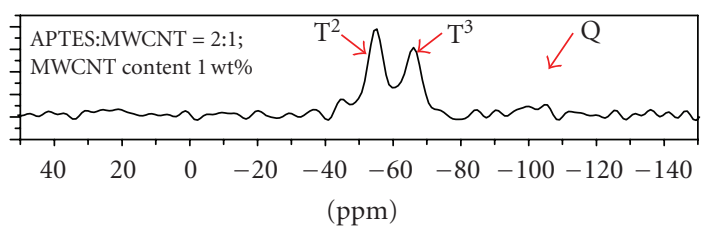

(c)

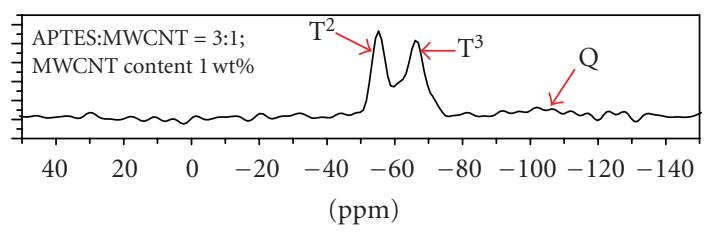

(e)

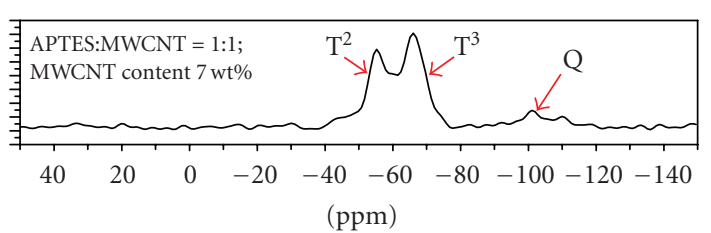

(b)

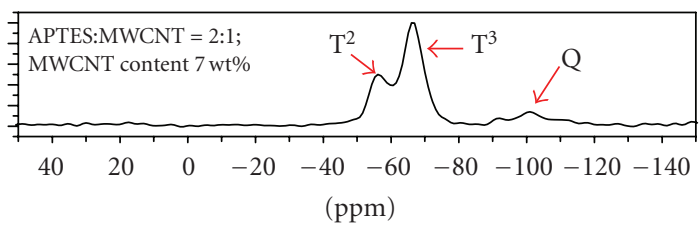

(d)

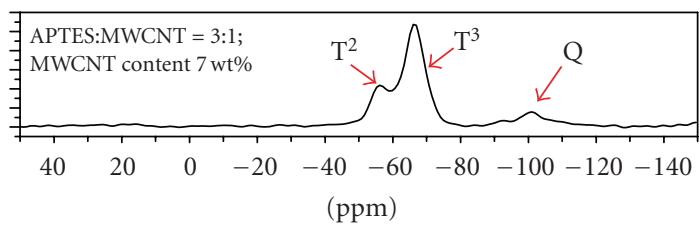

(f)

FIGURE $3:{ }^{29} \mathrm{Si}$ solid-state NMR spectra of cured APTES-MWCNT/polyimide composites.<smiles>CO[Si](OC)(OC)O[Si](O)(O)Br</smiles><smiles>CO[Si]([14CH3])(O[Si](O)(OC)OC)O[Si](OC)(OC)OC</smiles><smiles>[B][Si]1(OC)O[Si](OC)(OC)O[Si](OC)(OC)O[Si](OC)(OC)O[Si](OC)(OC)O1</smiles>

(a)<smiles>CO[Si](O)(O)O[Si](OC)(O[Si](O)(O)OC)O[Si](O)(O[Si](O)(O)O[Si](O)(O)O)O[Si](O)(O)O[Si](O)(O)O</smiles>

(b)

Figure 4: Structure of (a) trisubstituted siloxane bonds (T shift) [27] and (b) tetrasubstituted siloxane bonds (Q shift) [27].

not easily form an interpenetrating network. The TEM microphotograph shows that concentrations were different even with the same content $(7.0 \mathrm{wt} \%)$ APTES-MWCNT. APTES-MWCNT-3 show less concentrated than that of APTES-MWCNT-1 and APTES-MWCNT-2 in polyimide matrix with $7.0 \mathrm{wt} \%$ MWCNT content. APTES-MWCNT1 and APTES-MWCNT-2 show similar concentration in polyimide matrix with $7.0 \mathrm{wt} \%$ MWCNT content. However, the lengths of the assembled MWCNT were different. Assembled APTES-MWCNT-3 is longer than that of 


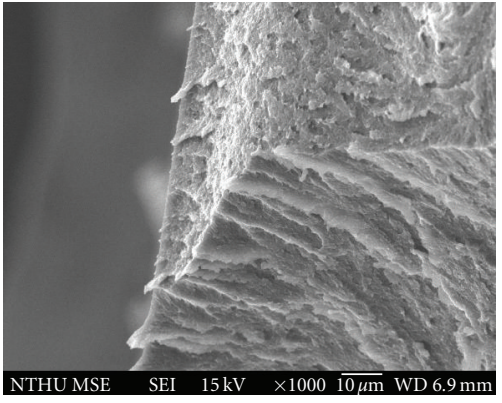

(a)

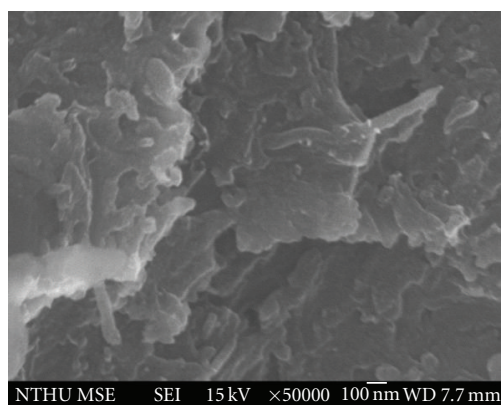

(d)

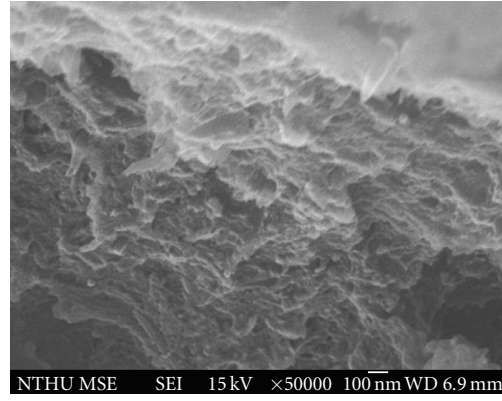

(b)

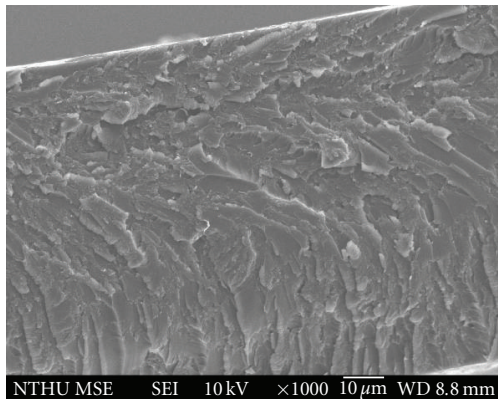

(e)

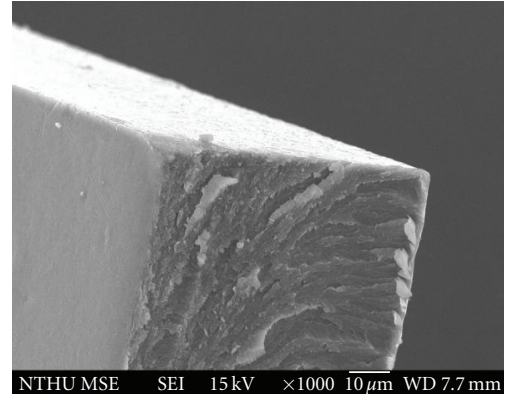

(c)

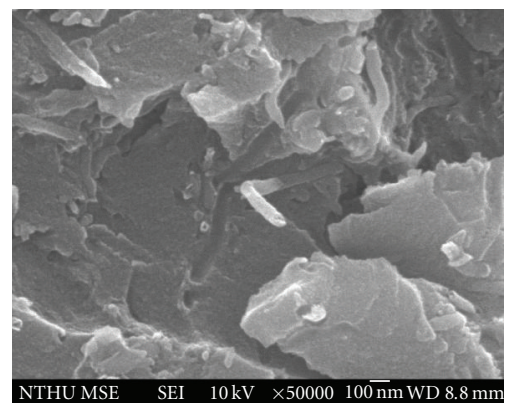

(f)

FIGURE 5: SEM microphotograph of $7.0 \mathrm{wt} \%$ APTES-MWCNT/polyimide composites: (a) APTES-MWCNT-1 ( $\times 1000)$, (b) APTESMWCNT-1 (×50 000), (c) APTES-MWCNT-2 (×1000), (d) APTES-MWCNT-2 (×50 000), (e) APTES-MWCNT-3 (×1000), and (f) APTESMWCNT-3 $(\times 50000)$.

APTES-MWCNT-2 and APTES-MWCNT-1 in the polyimide matrix. APTES-MWCNT-3 was connected with "head-totail" and the APTES-MWCNT-3 assembled to long, thin "needle shaped." The quantity of MWCNT of $7.0 \mathrm{wt} \%$ APTES-MWCNT-3 in polyimide matrix was similar to the $7.0 \mathrm{wt} \%$ APTES-MWCNT-2 and APTES-MWCNT-1.

\subsection{Electrical properties}

CNTs have a high aspect ratio and contain numerous $\pi$ bonds $(\mathrm{C}=\mathrm{C}$ bond). Electrical charges may be transferred through the $\pi$-bond ( $\mathrm{C}=\mathrm{C}$ bond) of CNTs. Adding a small quantity of CNT to the polymer matrix substantially reduces the surface and volume electrical resistivities of the matrix.

Figures 7(a) and 7(b) plot the surface and volume electrical resistivities of the APTES-MWCNT/polyimide composites. The surface resistivities were summarized in Table 3 and the volume resistivities were summarized in Table 4 . When unmodified and acid-modified MWCNT were utilized, the surface electrical resistivity of the composites decreased from $1.28 \times 10^{15} \Omega / \mathrm{cm}^{2}$ (neat polyimide) to $7.59 \times 10^{6} \Omega / \mathrm{cm}^{2}$ (a decrease of nine orders of magnitude with $7.0 \mathrm{wt} \%$ unmodified MWCNT) and to $2.53 \times 10^{9} \Omega / \mathrm{cm}^{2}$ (a decrease of six orders of magnitude with $7.0 \mathrm{wt} \%$ acid-modified CNT) (Figure 7(a)). The volume electrical resistivity of the composites decreased from $1.53 \times 10^{17} \Omega \mathrm{cm}$ (neat polyimide) to $4.09 \times 10^{4} \Omega \mathrm{cm}$ (a decrease of 13 orders of magnitude with $7.0 \mathrm{wt} \%$ unmodified MWCNT), and $2.66 \times 10^{8} \Omega \mathrm{cm}$ (a decrease in nine order of magnitude with $7.0 \mathrm{wt} \%$ acidmodified CNT), (Figure 7(b)). In the APTES-MWCNT system, the surface electrical resistivity of the composites decreased by five orders of magnitude from $1.28 \times 10^{15} \Omega / \mathrm{cm}^{2}$ (neat polyimide) to $8.64 \times 10^{10} \Omega / \mathrm{cm}^{2}$ (for $7.0 \mathrm{wt} \%$ APTESMWCNT-1/polyimde composites), by four orders of magnitude to $8.58 \times 10^{11} \Omega / \mathrm{cm}^{2}$ (with $7.0 \mathrm{wt} \%$ APTES-MWCNT2/polyimide composites), and by four orders of magnitude to $4.53 \times 10^{11} \Omega / \mathrm{cm}^{2}$ (with $7.0 \mathrm{wt} \%$ APTES-MWCNT3/polyimide composites) (Figure 7(a)). The volume electrical resistivity of the composites decreased by four orders of magnitude from $1.53 \times 10^{17} \Omega \mathrm{cm}$ (neat polyimide) to $5.07 \times 10^{11} \Omega \mathrm{cm}$ (with $7.0 \mathrm{wt} \%$ APTES-MWCNT1/polyimide composites), by eight orders of magnitude to $1.68 \times 10^{9} \Omega \mathrm{cm}$ (with $7.0 \mathrm{wt} \%$ APTES-MWCNT2/polyimide composites), and by seven orders of magnitude to $2.90 \times 10^{10} \Omega \mathrm{cm}(7.0 \mathrm{wt} \%$ APTES-MWCNT-3/polyimide composites) (Figure 7(b)).

Acid-modified MWCNTs and APTES-MWCNTs provide less improved surface and volume electricity conductivities than unmodified MWCNTs over MWCNT/polyimide nanocomposites. The MWCNTs may be shortened and the number of defects increased during acid modification. Our previous study revealed that unmodified MWCNTs were aggregated, but acid-modified MWCNT were dispersed in the polyimide matrix [17]. The aggregated MWCNTs may connect to each other and more easily form charge-conducting pathways. The model of the 


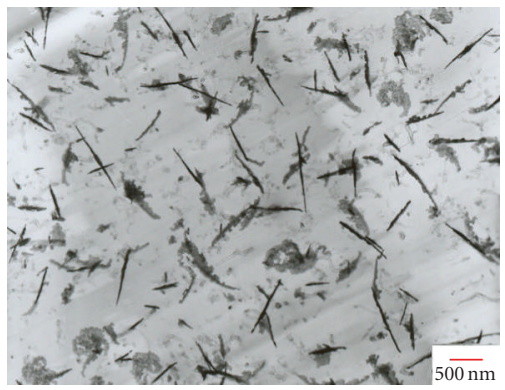

(a)



(d)

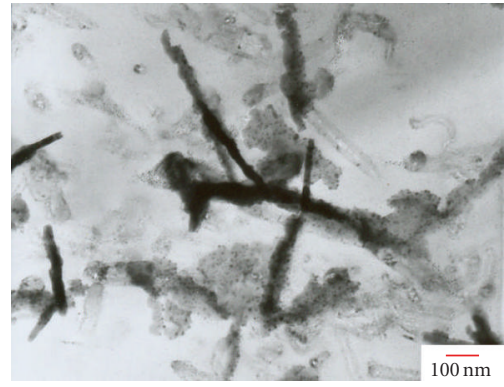

(b)

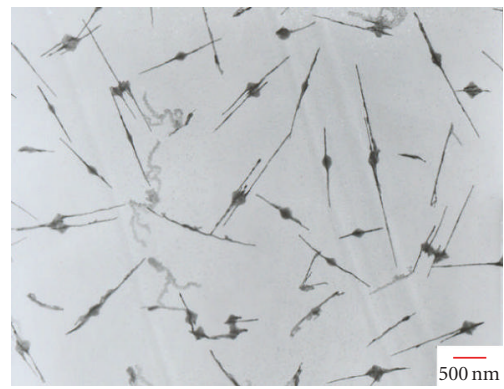

(e)

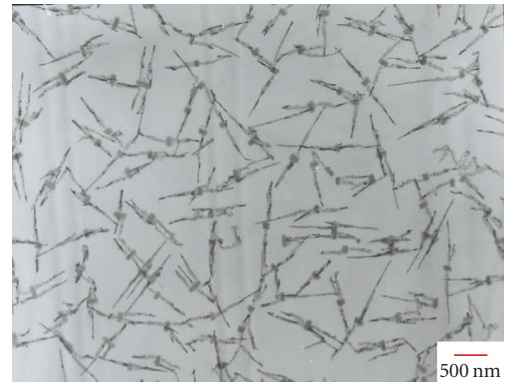

(c)

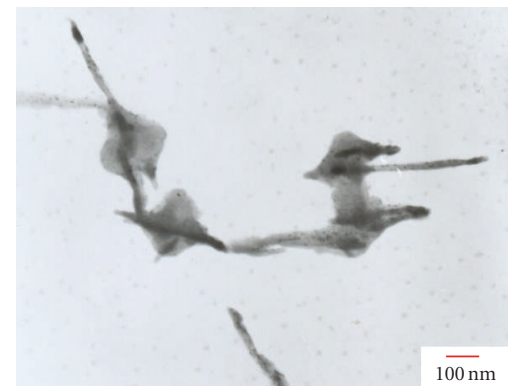

(f)

FIGURE 6: TEM microphotograph of $7.0 \mathrm{wt} \%$ APTES-MWCNT/polyimide composites APTES-MWCNT-1 (a) $\times 10000$, (b) $\times 50000$ APTESMWCNT-2, (c) $\times 10000$, (d) $\times 50000$ APTES-MWCNT-3, (e) $\times 10000$, (f) $\times 50000$.

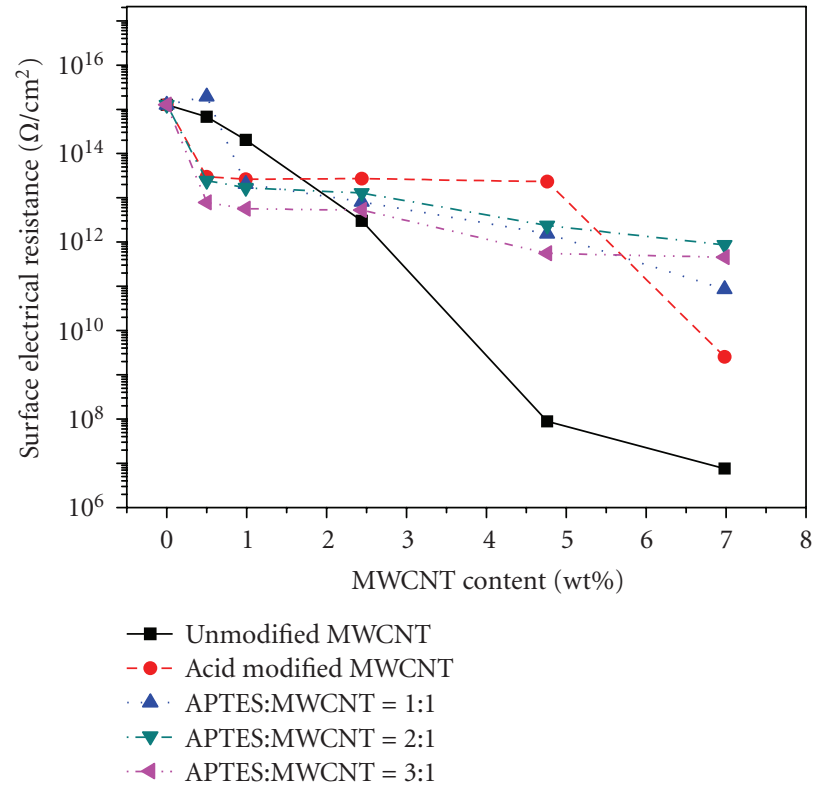

(a)

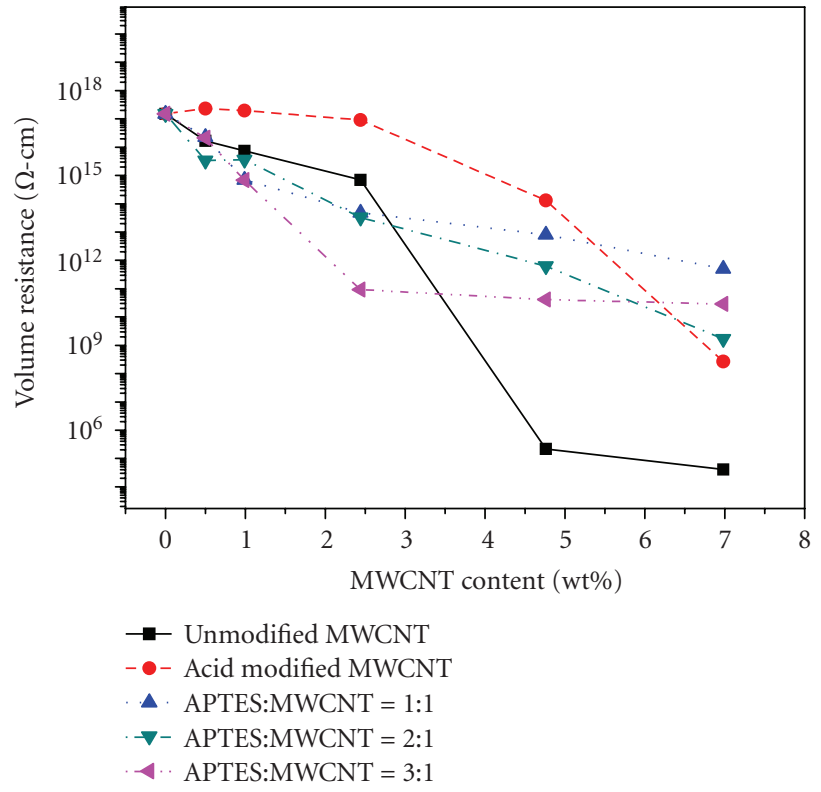

(b)

FIGURE 7: Electrical resisitivity of MWCNT/polyimide composites: (a) surface resistance and (b) volume resistance.

aggregated unmodified MWCNT is similar to that presented in Figure 8(a) and the electrical charge conducting model of the small amount of dispersed acid-modified MWCNT is similar to that shown in Figure 8(b). Figure 7(b) reveals that the APTES-MWCNT/polyimide composites have a lower percolation threshold (1.0 wt $\%$ for APTES-MWCNT-1 and APTES-MWCNT-2 and $2.4 \mathrm{wt} \%$ for APTES-MWCNT3) than that of the unmodified MWCNT/polyimide (4.76 wt\%) or acid-modified MWCNT/polyimide (more than $6.98 \mathrm{wt} \%)$. APTES-MWCNT-3 has a higher percolation threshold than APTES-MWCNT-1 and APTESMWCNT-2 in the polyimide matrix, perhaps because 


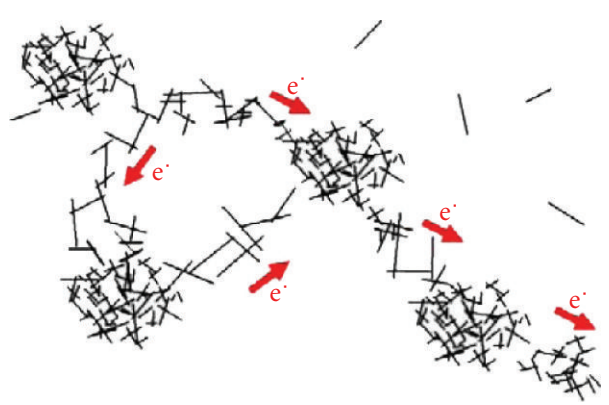

(a)

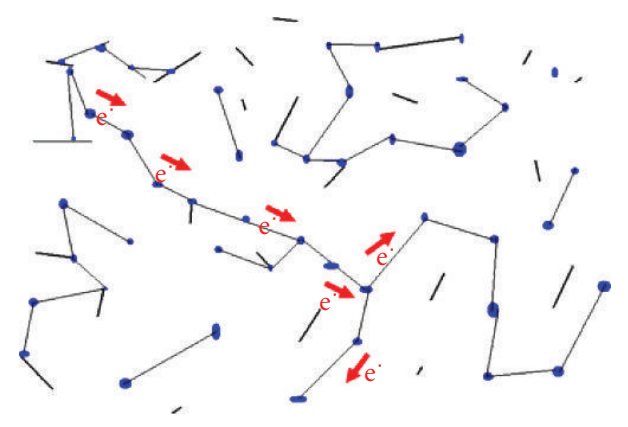

(c)

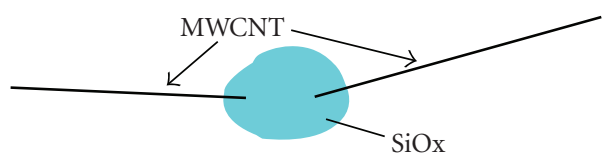

(e)

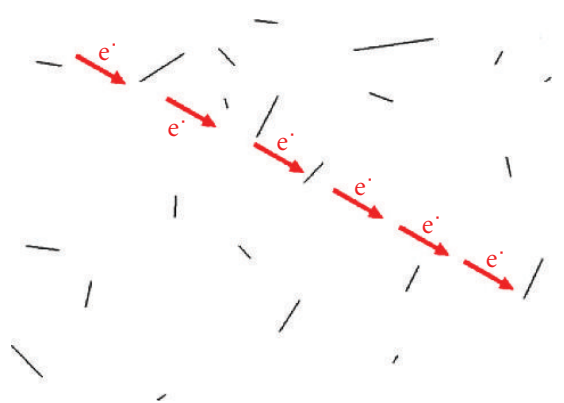

(b)

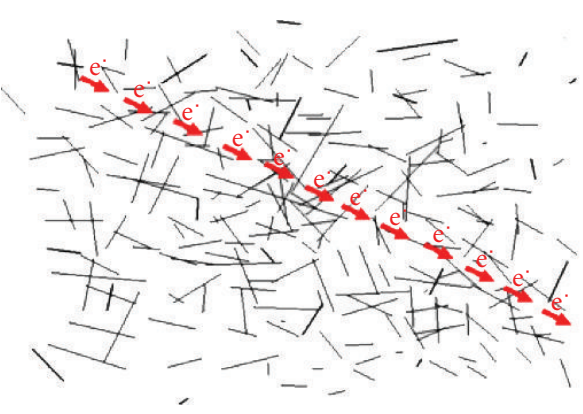

(d)

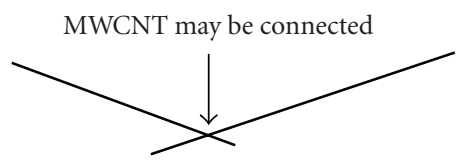

(f)

FIGURE 8: Diagram of electrical charge transfer on (a) aggregated conductivity material, (b) small amount of dispersed conductivity material, (c) conductivity material connect each other, (d) large amount of dispersed conductivity material, (e) Junction of connected APTESMWCNT, (f) Junction of connected unmodified or acid-modified MWCNT over percolation threshold.

TABLE 4: Volume electrical resistivity of MWCNT/polyimide composites.

\begin{tabular}{|c|c|c|c|c|c|}
\hline MWCNT content & $\begin{array}{l}\text { Volume electrical } \\
\text { resistivity of } \\
\text { unmodified } \\
\text { MWCNT/PI, } \\
\Omega-\mathrm{cm}\end{array}$ & $\begin{array}{l}\text { Volume electrical } \\
\text { resistivity of } \\
\text { acid-modified } \\
\text { MWCNT/PI, } \\
\Omega-\mathrm{cm}\end{array}$ & $\begin{array}{l}\text { Volume electrical } \\
\text { resistivity of } \\
\text { APTES- } \\
\text { MWCNT-1/PI, } \\
\Omega \text {-cm }\end{array}$ & $\begin{array}{l}\text { Volume electrical } \\
\text { resistivity of } \\
\text { APTES- } \\
\text { MWCNT-2/PI, } \\
\Omega \text {-cm }\end{array}$ & $\begin{array}{l}\text { Volume electrical } \\
\text { resistivity of } \\
\text { APTES- } \\
\text { MWCNT-3/PI, } \\
\Omega \text {-cm }\end{array}$ \\
\hline 0 & $1.53 \times 10^{17}$ & $1.53 \times 10^{17}$ & $1.53 \times 10^{17}$ & $1.53 \times 10^{17}$ & $1.53 \times 10^{17}$ \\
\hline 0.5 & $1.69 \times 10^{16}$ & $2.33 \times 10^{17}$ & $2.30 \times 10^{16}$ & $3.37 \times 10^{15}$ & $2.13 \times 10^{16}$ \\
\hline 1.0 & $7.52 \times 10^{15}$ & $1.95 \times 10^{17}$ & $6.94 \times 10^{14}$ & $3.61 \times 10^{15}$ & $6.90 \times 10^{14}$ \\
\hline 2.4 & $7.08 \times 10^{14}$ & $9.25 \times 10^{16}$ & $4.82 \times 10^{13}$ & $3.27 \times 10^{13}$ & $9.24 \times 10^{10}$ \\
\hline 4.8 & $219 \times 10^{5}$ & $1.33 \times 10^{14}$ & $8.11 \times 10^{12}$ & $6.19 \times 10^{11}$ & $4.07 \times 10^{10}$ \\
\hline 7.0 & $409 \times 10^{4}$ & $2.66 \times 10^{8}$ & $5.07 \times 10^{11}$ & $1.68 \times 10^{9}$ & $2.90 \times 10^{10}$ \\
\hline
\end{tabular}

APTES-MWCNT-3 cannot form an interpenetrating network easier than APTES-MWCNT-1 and APTES-MWCNT-2 can.

When the MWCNT content is high $(7.0 \mathrm{wt} \%)$, the volume electrical resistivities of APTES-MWCNT/polyimide composites exceed those of unmodified and acid-modified MWCNT/polyimide composites. Figures 7(a) and 7(b) show that when the MWCNT content was lower than $7.0 \mathrm{wt} \%$,
APTES-MWCNT/polyimide composites had a lower surface and volume electrical resistivity than those of acid-modified MWCNT/polyimide composites. The electrical charge transfer model of the APTES-MWCNT in polyimide matrix is similar to that presented in Figure 8(c). The TEM microphotograph indicates that some of the APTES-MWCNTs are connected to each other in the polyimide matrix and the charge transfer pathways may be more effective than 




(a)

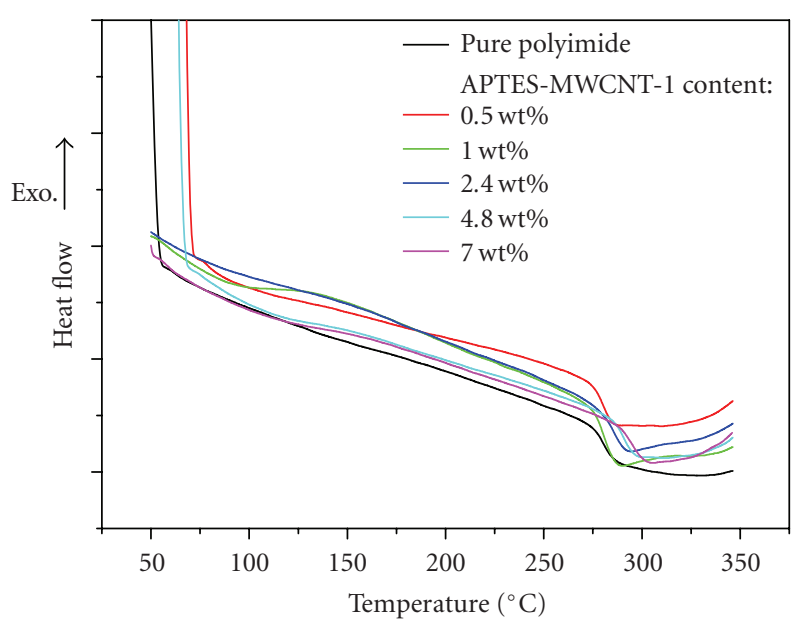

(c)

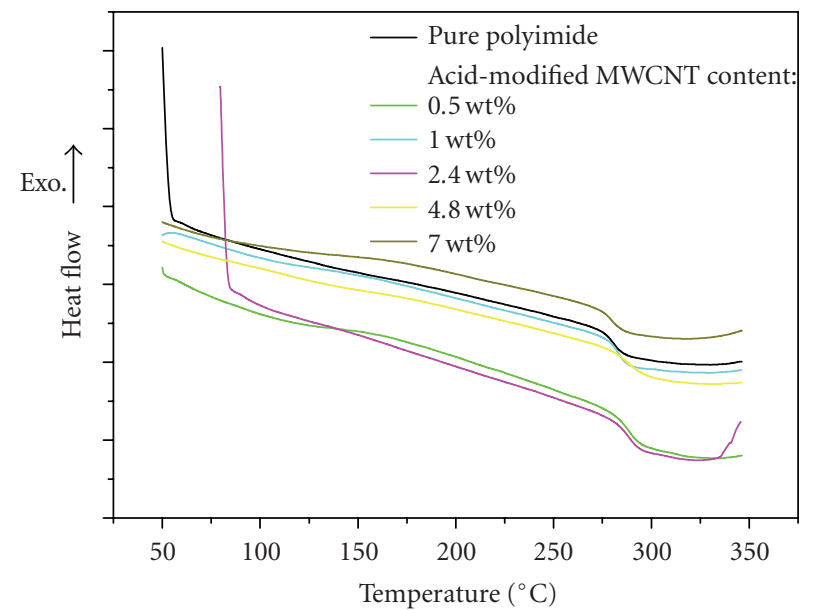

(b)

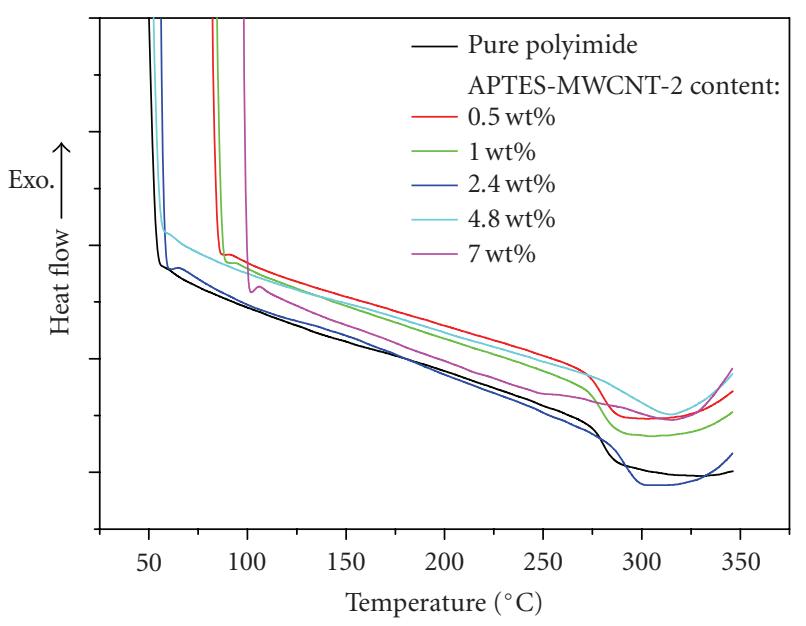

(d)

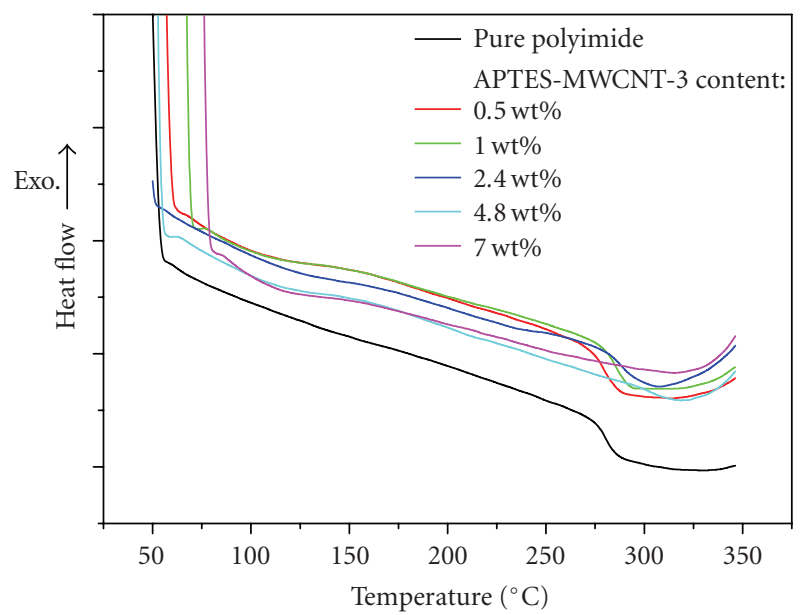

(e)

FigurE 9: DSC data of the MWCNTs/polyimide composites: (a) unmodified MWCNT, (b) acid-modified MWCNT, (c) APTES-MWCNT-1, (d) APTES-MWCNT-2, (e) APTES-MWCNT-3. 
TABLE 5: Tg of MWCNT/polyimide composites.

\begin{tabular}{lccccc}
\hline $\begin{array}{l}\text { MWCNT } \\
\text { content }\end{array}$ & $\begin{array}{c}\text { Tg of unmodified } \\
\text { MWCNT/PI, }{ }^{\circ} \mathrm{C}\end{array}$ & $\begin{array}{c}\text { Tg of acid-modified } \\
\text { MWCNT/PI, }{ }^{\circ} \mathrm{C}\end{array}$ & $\begin{array}{c}\text { Tg of APTES- } \\
\text { MWCNT-1/PI, }{ }^{\circ} \mathrm{C}\end{array}$ & $\begin{array}{l}\text { Tg of APTES- } \\
\text { MWCNT-2/PI, }{ }^{\circ} \mathrm{C}\end{array}$ & $\begin{array}{l}\text { Tg of APTES- } \\
\text { MWCNT-3/PI, }{ }^{\circ} \mathrm{C}\end{array}$ \\
\hline 0 & 281.1 & 281.1 & 281.1 & 281.1 & 281.1 \\
0.5 & 280.2 & 281.8 & 280.5 & 279.9 & 279.0 \\
1.0 & 278.6 & 284.8 & 280.6 & 29.9 & 285.7 \\
2.4 & 278.7 & 285.3 & 285.7 & 293.9 & 303.7 \\
4.8 & 278.4 & 285.2 & 290.8 & 294.9 & - \\
7.0 & 276.5 & 288.4 & 295.2 & & 28.5 \\
\hline
\end{tabular}

TABLE 6: Tensile strength of MWCNT/polyimide composites.

\begin{tabular}{lccccc}
\hline MWCNT content & $\begin{array}{l}\text { Tensile strength } \\
\text { of unmodified } \\
\text { MWCNT/PI, MPa }\end{array}$ & $\begin{array}{l}\text { Tensile strength of } \\
\text { acid-modified } \\
\text { MWCNT/PI, MPa }\end{array}$ & $\begin{array}{l}\text { Tensile strength of } \\
\text { APTES-MWCNT- } \\
\text { 1/PI, MPa }\end{array}$ & $\begin{array}{l}\text { Tensile strength of } \\
\text { APTES-MWCNT- } \\
\text { 2/PI, MPa }\end{array}$ & $\begin{array}{c}\text { Tensile strength of } \\
\text { APTES-MWCNT- } \\
\text { 3/PI, MPa }\end{array}$ \\
\hline 0 & $101.71 \pm 5.10$ & $101.71 \pm 5.10$ & $101.71 \pm 5.10$ & $101.71 \pm 5.10$ & $101.71 \pm 5.10$ \\
0.5 & $107.37 \pm 5.66$ & $106.91 \pm 7.24$ & $121.53 \pm 5.21$ & $125.55 \pm 5.12$ & $125.00 \pm 8.25$ \\
1.0 & $110.67 \pm 5.66$ & $110.02 \pm 5.23$ & $126.49 \pm 9.68$ & $126.66 \pm 9.96$ & $128.03 \pm 6.32$ \\
2.4 & $111.56 \pm 10.00$ & $115.44 \pm 7.46$ & $126.03 \pm 7.34$ & $116.90 \pm 6.00$ & $117.44 \pm 8.46$ \\
4.8 & $118.11 \pm 6.11$ & $129.42 \pm 6.63$ & $101.01 \pm 8.50$ & $106.91 \pm 5.02$ & $109.64 \pm 7.40$ \\
7.0 & $120.87 \pm 10.834$ & $133.84 \pm 5.37$ & $104.24 \pm 9.07$ & $82.39 \pm 4.24$ & Too brittle \\
\hline
\end{tabular}

those of unmodified and acid-modified MWCNT. When the MWCNT content is higher than $7.0 \mathrm{wt} \%$, the charge transfer pathway may be formed (Figure $8(d)$ ) in acid-modified MWCNT polyimide composites. Some of the APTESs were not bonded with the acid-modified MWCNT, which may bond to the polyamic acid and form a complex [1, 28]. Furthermore, as presented in Figure 8(e), although the APTESMWCNTs connected with each other in the polyimide matrix, the MWCNTs were separated by SiOx. When the unmodified and acid-modified MWCNT contents were very high, the MWCNTs may be interconnected (Figure 8(f)). The results show that when the MWCNT content exceeds $7.0 \mathrm{wt} \%$, APTES-MWCNT/polyimide composites have a higher surface and volume electrical resistivity than those of acid-modified MWCNT/polyimide composites.

\subsection{Glass transition temperature (Tg)}

The glass transition temperatures (Tgs) of the polymer matrix depend on the free volume of the polymer, which is related to the affinity between the filler and the polymer matrix. A polymer with a lower free volume generally has a higher Tg. A polymer matrix with a higher affinity to filler exhibited less polymer molecular motion and reduced the free volume of the polymer molecules $[32,33]$. The $-\mathrm{COOH}$ functional groups on the acid-modified MWCNT surface can form hydrogen bonds with the imide functional groups of the polyimide, reducing the free volume of the polymer. When the APTES-MWCNT/polyamic acid was heated to $300^{\circ} \mathrm{C}$, the silane molecules on the MWCNT surface reacted and connected with each other. The free volume of the polymer is reduced and molecular motion is restricted.

Figure 9 shows the DSC data of the MWCNT/polyimide composites. The glass transition temperatures (Tgs) of the MWCNT/polyimide composites were summarized in Table 5. When $1.0 \mathrm{wt} \%$ unmodified MWCNT was added to the matrix, Tg decreased slightly. The Tg of $1.0 \mathrm{wt} \%$ unmodified MWCNT/polyimide is $279^{\circ} \mathrm{C}$. When the unmodified MWCNT content was $7.0 \mathrm{wt} \%$, Tg decreased to $277^{\circ} \mathrm{C}$. The affinity between the unmodified MWCNT and the polyimide was poor, so the free volume of the composites increased and $\mathrm{Tg}$ decreased. The glass transition temperature $(\mathrm{Tg})$ of the pristine polyimide was $280.44^{\circ} \mathrm{C}$. When acid-modified MWCNTs were utilized, the Tg of the MWCNT/polyimide composites increased slightly to $287.45^{\circ} \mathrm{C}(2.4 \mathrm{wt} \%$ acidmodified MWCNT/polyimide composites). When the acidmodified MWCNT content was $7.0 \mathrm{wt} \%$, Tg decreased slightly to $284.09^{\circ} \mathrm{C}$. When the APTES-MWCNT content was high, $\mathrm{Tg}$ increased significantly. The $\mathrm{Tg}$ of the APTES-MWCNT/polyimide composites increased to $295.22^{\circ} \mathrm{C} \quad(7.0 \mathrm{wt} \%$ APTES-MWCNT-1/polyimide composites), $294.88^{\circ} \mathrm{C}(7.0 \mathrm{wt} \%$ APTES-MWCNT-2/polyimide composites), and to $303.69^{\circ} \mathrm{C}(4.8 \mathrm{wt} \%$ APTES-MWCNT$3 /$ polyimide composites). The results show that $\mathrm{Tg}$ increased with the ratio of APTES to MWCNT, since silane may restrict the molecular motion of the polyimide matrix.

\subsection{Tensile properties}

The mechanical properties of MWCNT/polymer composites depend on the affinity of the MWCNTs to the polymer matrix. Since modified MWCNTs have a greater affinity to the polymer matrix than that of unmodified MWCNTs, modified MWCNTs improve the tensile properties of the polyimide significantly. Hydrogen atoms at the $-\mathrm{COOH}$ groups of acid-modified MWCNTs may form hydrogen bonds with the $\mathrm{C}=\mathrm{O}$ bonds of the PI molecules $[31,32]$. 
TABLE 7: Young's modulus of MWCNT/polyimide composites.

\begin{tabular}{lccccc}
\hline $\begin{array}{l}\text { MWCNT } \\
\text { content }\end{array}$ & $\begin{array}{l}\text { Young's modulus } \\
\text { of unmodified } \\
\text { MWCNT/PI, GPa }\end{array}$ & $\begin{array}{l}\text { Young's modulus } \\
\text { of acid-modified } \\
\text { MWCNT/PI, GPa }\end{array}$ & $\begin{array}{l}\text { Young's modulus } \\
\text { of APTES-MWCNT- } \\
\text { 1/PI, GPa }\end{array}$ & $\begin{array}{l}\text { Young's modulus } \\
\text { of APTES-MWCNT- } \\
\text { 2/PI, GPa }\end{array}$ & $\begin{array}{l}\text { Young's modulus } \\
\text { of APTES-MWCNT- } \\
3 / \text { PI, GPa }\end{array}$ \\
\hline 0 & $2.34 \pm 0.12$ & $2.34 \pm 0.12$ & $2.34 \pm 0.12$ & $2.34 \pm 0.12$ & $2.34 \pm 0.12$ \\
0.5 & $2.41 \pm 0.29$ & $3.08 \pm 0.23$ & $3.71 \pm 0.24$ & $3.95 \pm 0.25$ & $3.45 \pm 0.18$ \\
1.0 & $2.52 \pm 0.12$ & $3.20 \pm 0.25$ & $3.81 \pm 0.19$ & $4.04 \pm 0.22$ & $3.52 \pm 0.21$ \\
2.4 & $3.05 \pm 0.12$ & $3.68 \pm 0.11$ & $3.75 \pm 0.25$ & $3.74 \pm 0.22$ & $3.48 \pm 0.28$ \\
4.8 & $3.15 \pm 0.18$ & $3.60 \pm 0.25$ & $3.49 \pm 0.18$ & $3.62 \pm 0.12$ & $3.48 \pm 0.30$ \\
7.0 & $3.19 \pm 0.15$ & $3.66 \pm 0.29$ & $3.54 \pm 0.19$ & $3.17 \pm 0.21$ & Too brittle \\
\hline
\end{tabular}

Tables 6 and 7 exhibit the tensile properties of the MWCNT/polyimide composites. The tensile strength of neat polyimide is $101.71 \mathrm{MPa}$. The APTES-MWCNT/polyimide exhibits a maximum tensile strength at the MWCNT content of $1.0 \mathrm{wt} \%$. When $1.0 \mathrm{wt} \%$ APTES-MWCNT was employed, the tensile strength increased to $126.49 \mathrm{MPa}$ (increased 24.36\%) (APTES-MWCNT-1), to $126.66 \mathrm{MPa}$ (increased $24.53 \%$ ) (APTES-MWCNT-2), and to $128.03 \mathrm{MPa}$ (increased 25.88\%) (APTES-MWCNT-3) (Table 6). However, if the MWCNT content exceeds $1.0 \mathrm{wt} \%$, the tensile strength declines. Table 7 shows the Young's modulus of the APTES-MWCNT/polyimide composites. The Young's modulus of neat polyimide was $2.34 \mathrm{GPa}$. When $1.0 \mathrm{wt} \%$ acid-modified MWCNT was used, the Young's modulus increased to $3.68 \mathrm{GPa}$ (increased $57.73 \%$ ). When $1.0 \mathrm{wt} \%$ APTES-MWCNT was used, the Young's modulus increased to $3.81 \mathrm{GPa}$ (increase $62.82 \%$ ) (APTES-MWCNT1 ), to $4.04 \mathrm{GPa}$ (increase $71.79 \%$ ) (APTES-MWCNT-2), and to $3.51 \mathrm{GPa}$ (increase 50.00\%) (APTES-MWCNT-3) (Table 7). When the APTES-MWCNT (APTES-MWCNT1 and APTES-MWCNT-2) content exceeds $1.0 \mathrm{wt} \%$, the Young's modulus decreased. When the APTES-MWCNT1 and APTES-MWCNT-2 contents were $7.0 \mathrm{wt} \%$, Young's modulus decreased to $3.54 \mathrm{GPa}$ (APTES-MWCNT-1) and 3.17 GPa (APTES-MWCNT-2). When the APTES-MWCNT3 contents were $4.8 \mathrm{wt} \%$, Young's modulus increased to $3.48 \mathrm{GPa}$.

TEM microphotograph shows that some of the APTESMWCNTs were connected together in the polyimide matrix. MWCNT network may be formed in the polyimide matrix. When MWCNTs networks were formed in the polyimide matrix, it can be improve the tensile strength more significantly than that of acid-modified MWCNT. Tai et al. [36] reported that the network MWCNT improved the mechanical properties significantly more than that of dispersed MWCNT. They proposed that the lengths of MWCNTs in network were longer [33]. When APTES-MWCNT content was higher than $2.4 \mathrm{wt} \%$, the composites possess lower tensile strength and Young's modulus decreased slightly. The composites became brittle when APTES-MWCNT content is high.

\section{CONCLUSION}

Aminosilane-modified MWCNT/polyimide nanocomposites have been prepared. ${ }^{29} \mathrm{Si}$ solid state NMR demonstrates that $\mathrm{T}$ substituted and $\mathrm{Q}$ substituted siloxane bonds are present in APTES-MWCNT/polyimide composites. A TEM microphotograph shows that MWCNTs may connect to each other in the polyimide matrix, MWCNT network, and that polyimide molecules may interpenetrate the crosslinked MWCNT network.

The surface and volume electrical resistivity of the APTES-MWCNT/polyimide composites decreased more significantly than that of acid-modified MWCNT/polyimide composites when the APTES-MWCNTs content was lower than $4.8 \mathrm{wt} \%$, the percolation threshold of the APTESMWCNT/polyimide composites was lower than that of the unmodified and acid-modified MWCNT/polyimide composites. The surface electrical resistivity of the polyimide decreased from $1.28 \times 10^{15} \Omega / \mathrm{cm}^{2}$ (neat polyimide) to $2.73 \times 10^{13} \Omega-\mathrm{cm}(2.4 \mathrm{wt} \%$ acid modified MWCNT) and $8.07 \times 10^{12} \Omega-\mathrm{cm}(2.4 \mathrm{wt} \%$ APTES-MWCNT- 1$)$. The volume electrical resistivity of the polyimide decreased from $1.53 \times 10^{17} \Omega \mathrm{cm}$ (neat polyimide) to $9.25 \times 10^{16} \Omega \mathrm{cm}$ $\left(2.4 \mathrm{wt} \%\right.$ acid modified MWCNT) and $9.23 \times 10^{10} \Omega \mathrm{cm}$ (2.4 wt $\%$ APTES-MWCNT-2). The percolation thresholds of the unmodified MWCNT/polyimde, acid-modified MWCNT/polyimide, APTES- MWCNT-1/polyimide, APTESMWCNT-2/polyimide, and APTES-MWCNT-3/polyimide were $4.76 \mathrm{wt} \%$, more than $7.0 \mathrm{wt} \%, 1.0 \mathrm{wt} \%, 1.0 \mathrm{wt} \%$, and $2.4 \mathrm{wt} \%$, respectively.

The glass transition temperature ( $\mathrm{Tg}$ ) of the APTESMWCNT/polyimide composites increased more than those of unmodified and acid-modified MWCNT/polyimide composites. The $\mathrm{Tg}$ of polyimide increased from $281.1^{\circ} \mathrm{C}$ (neat polyimide) to $303.7^{\circ} \mathrm{C}$ (4.8 wt\% APTES-MWCNT-3).

Tensile strength of MWCNT/polyimide increase form 101.71 $\mathrm{MPa}$ (neat polyimide) to $120.87 \mathrm{MPa}(7.0 \mathrm{wt} \%$ unmodified MWCNT, increased 18.8\%), 132.87 MPa (7.0 wt $\%$ acid modified MWCNT, increased 30.6\%), $126.49 \mathrm{MPa}$ (1.0 wt $\%$ APTES-MWCNT-1, increased 24.4\%), 126.66 MPa (1.0 wt $\%$ APTES-MWCNT-2 increased, 24.5\%), and 128.03 MPa (1.0 wt\% APTES-MWCNT-3, increased 25.9\%)

\section{ACKNOWLEDGMENTS}

The authors would like to acknowledge the National Science Council of Taiwan for the financial support under Contract no. NSC 95-2221-E-007-081. 


\section{REFERENCES}

[1] D. Wilson, H. D. Stenzenberger, and P. M. Hergenrother, Polyimides, Chapman \& Hall, New York, NY, USA, 1990.

[2] S. Iijima, "Helical microtubules of graphitic carbon," Nature, vol. 354, no. 6348, pp. 56-58, 1991.

[3] J. Sandler, M. S. P. Shaffer, T. Prasse, W. Bauhofer, K. Schulte, and A. H. Windle, "Development of a dispersion process for carbon nanotubes in an epoxy matrix and the resulting electrical properties," Polymer, vol. 40, no. 21, pp. 5967-5971, 1999.

[4] H. Geng, R. Rosen, B. Zheng, et al., "Fabrication and properties of composites of poly(ethylene oxide) and functionalized carbon nanotubes," Advanced Materials, vol. 14, no. 19, pp. 1387-1390, 2002.

[5] M. S. Dresselhaus, G. Dresselhaus, and P. C. Eklund, Science of Fullerenes and Carbon Nanotubes, Academic Press, San Diego, Calif, USA, 1996.

[6] F. Béguin and P. Ehrburger, "Special issue on carbon nanotubes," Carbon, vol. 40, no. 10, p. 1619, 2002.

[7] S. Subramoney, "Novel nanocarbons-structure, properties, and potential applications," Advanced Materials, vol. 10, no. 15, pp. 1157-1171, 1998.

[8] B. I. Yakobson and R. E. Smalley, "Fullerene nanotubes: C1,000,000 and beyond," American Scientist, vol. 85, no. 4, pp. 324-337, 1997.

[9] T. McNally, P. Pötschke, P. Halley, et al., "Polyethylene multiwalled carbon nanotube composites," Polymer, vol. 46, no. 19, pp. 8222-8232, 2005.

[10] W. Tang, M. H. Santare, and S. G. Advani, "Melt processing and mechanical property characterization of multi-walled carbon nanotube/high density polyethylene (MWNT/HDPE) composite films," Carbon, vol. 41, no. 14, pp. 2779-2785, 2003.

[11] M.-K. Seo, J.-R. Lee, and S.-J. Park, "Crystallization kinetics and interfacial behaviors of polypropylene composites reinforced with multi-walled carbon nanotubes," Materials Science and Engineering A, vol. 404, no. 1-2, pp. 79-84, 2005.

[12] Z. Yang, B. Dong, Y. Huang, L. Liu, F.-Y. Yan, and H.-L. Li, "A study on carbon nanotubes reinforced poly(methyl methacrylate) nanocomposites," Materials Letters, vol. 59, no. 17, pp. 2128-2132, 2005.

[13] H. Zeng, C. Gao, Y. Wang, et al., "In situ polymerization approach to multiwalled carbon nanotubes-reinforced nylon 1010 composites: mechanical properties and crystallization behavior," Polymer, vol. 47, no. 1, pp. 113-122, 2006.

[14] A. Yu, H. Hu, E. Bekyarova, et al., "Incorporation of highly dispersed single-walled carbon nanotubes in a polyimide matrix," Composites Science and Technology, vol. 66, no. 9, pp. 1190-1197, 2006.

[15] D. M. Delozier, K. A. Watson, J. G. Smith Jr., T. C. Clancy, and J. W. Connell, "Investigation of aromatic/aliphatic polyimides as dispersants for single wall carbon nanotubes," Macromolecules, vol. 39, no. 5, pp. 1731-1739, 2006.

[16] B.-K. Zhu, S.-H. Xie, Z.-K. Xu, and Y.-Y. Xu, "Preparation and properties of the polyimide/multi-walled carbon nanotubes (MWNTs) nanocomposites," Composites Science and Technology, vol. 66, no. 3-4, pp. 548-554, 2006.

[17] S.-M. Yuen, C.-C. M. Ma, Y.-Y. Lin, and H.-C. Kuan, "Preparation, morphology and properties of acid and amine modified multiwalled carbon nanotube/polyimide composite," Composites Science and Technology, vol. 67, no. 11-12, pp. 25642573, 2007.
[18] A. Hirsch, "Functionalization of single-walled carbon nanotubes," Angewandte Chemie International Edition, vol. 41, no. 11, pp. 1853-1859, 2002.

[19] C. Velasco-Santos, A. L. Martínez-Hernández, M. LozadaCassou, A. Alvarez-Castillo, and V. M. Castaño, "Chemical functionalization of carbon nanotubes through an organosilane," Nanotechnology, vol. 13, no. 4, pp. 495-498, 2002.

[20] A. M. Shanmugharaj, J. H. Bae, K. Y. Lee, W. H. Noh, S. H. Lee, and S. H. Ryu, "Physical and chemical characteristics of multiwalled carbon nanotubes functionalized with aminosilane and its influence on the properties of natural rubber composites," Composites Science and Technology, vol. 67, no. 9, pp. 18131822, 2007.

[21] P. C. Ma, J.-K. Kim, and B. Z. Tang, "Functionalization of carbon nanotubes using a silane coupling agent," Carbon, vol. 44, no. 15, pp. 3232-3238, 2006.

[22] L. Vast, G. Philippin, A. Destrée, et al., "Chemical functionalization by a fluorinated trichlorosilane of multi-walled carbon nanotubes," Nanotechnology, vol. 15, no. 7, pp. 781-785, 2004.

[23] L. Valentini, J. Macan, I. Armentano, F. Mengoni, and J. M. Kenny, "Modification of fluorinated single-walled carbon nanotubes with aminosilane molecules," Carbon, vol. 44, no. 11, pp. 2196-2201, 2006.

[24] H.-L. Wu, C.-C. M. Ma, Y.-T. Yang, H.-C. Kuan, C.-C. Yang, and C.-L. Chiang, "Morphology, electrical resistance, electromagnetic interference shielding and mechanical properties of functionalized MWNT and poly(urea urethane) nanocomposites," Journal of Polymer Science Part B, vol. 44, no. 7, pp. 1096-1105, 2006.

[25] C.-F. Kuan, H.-C. Kuan, C.-C. M. Ma, C.-H. Chen, and H.$\mathrm{L}$. Wu, "The preparation of carbon nanotube/linear low density polyethylene composites by a water-crosslinking reaction," Materials Letters, vol. 61, no. 13, pp. 2744-2748, 2007.

[26] H.-L. Wu, Y.-T. Yang, C.-C. M. Ma, and H.-C. Kuan, "Molecular mobility of free-radical-functionalized carbonnanotube/siloxane/poly(urea urethane) nanocomposites," Journal of Polymer Science Part A, vol. 43, no. 23, pp. 6084-6094, 2005.

[27] K. J. Shea, D. A. Loy, and O. Webster, "Arylsilsesquioxane gel and related materials. New hybrids of organic and inorganic networks," Journal of the American Chemical Society, vol. 114, no. 17, pp. 6700-6710, 1992.

[28] K. L. Mittal, Polyimides: Synthesis, Characterization, and Applications, Plenum Press, New York, NY, USA, 1984.

[29] Y. J. Kim, T. S. Shin, H. D. Choi, J. H. Kwon, Y.-C. Chung, and H. G. Yoon, "Electrical conductivity of chemically modified multiwalled carbon nanotube/epoxy composites," Carbon, vol. 43, no. 1, pp. 23-30, 2005.

[30] D. Stauffer, Introduction to the Percolation Theory, Francis \& Taylor, London, UK, 1991.

[31] G. Hu, C. Zhao, S. Zhang, M. Yang, and Z. Wang, "Low percolation thresholds of electrical conductivity and rheology in poly(ethylene terephthalate) through the networks of multiwalled carbon nanotubes," Polymer, vol. 47, no. 1, pp. 480488, 2006.

[32] M. I. Chipara, "The glass transition phenomenon in macromolecular systems," Physica B, vol. 234-236, pp. 263-265, 1997.

[33] L. H. Sperling, Introduction to Physical Polymer Science, WileyInterscience, New York, NY, USA, 3rd edition, 2001.

[34] R. A. Nyquist, C. L. Putzig, T. L. Clark, and A. T. McDonald, "Infrared study of intramolecularly hydrogen bonded aromatic carbonyl containing compounds in various solvents," Vibrational Spectroscopy, vol. 12, no. 1, pp. 93-102, 1996. 
[35] V. Gutmann, The Donor-Acceptor Approach to Molecular Interactions, Plenum Press, New York, NY, USA, 1978.

[36] N.-H. Tai, M.-K. Yeh, and J.-H. Liu, "Enhancement of the mechanical properties of carbon nanotube/phenolic composites using a carbon nanotube network as the reinforcement," Carbon, vol. 42, no. 12-13, pp. 2774-2777, 2004. 

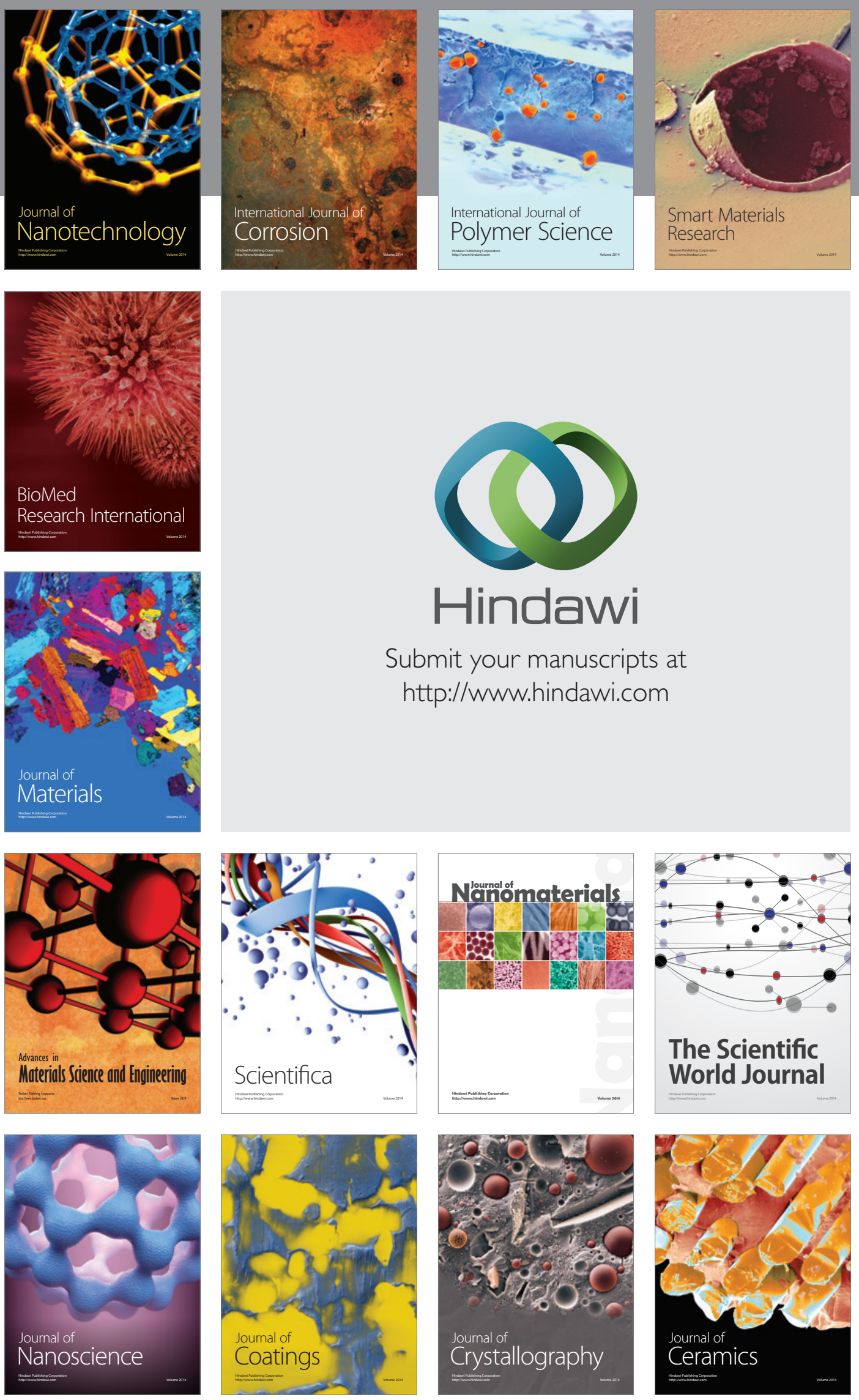

The Scientific World Journal

Submit your manuscripts at

http://www.hindawi.com

\section{World Journal}

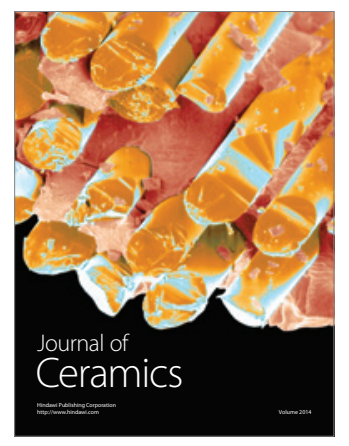

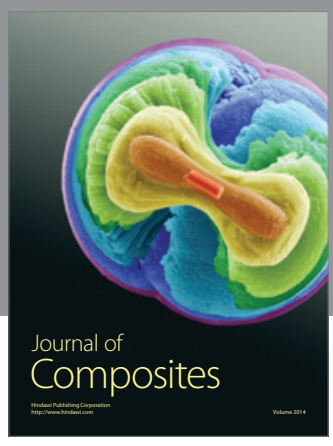
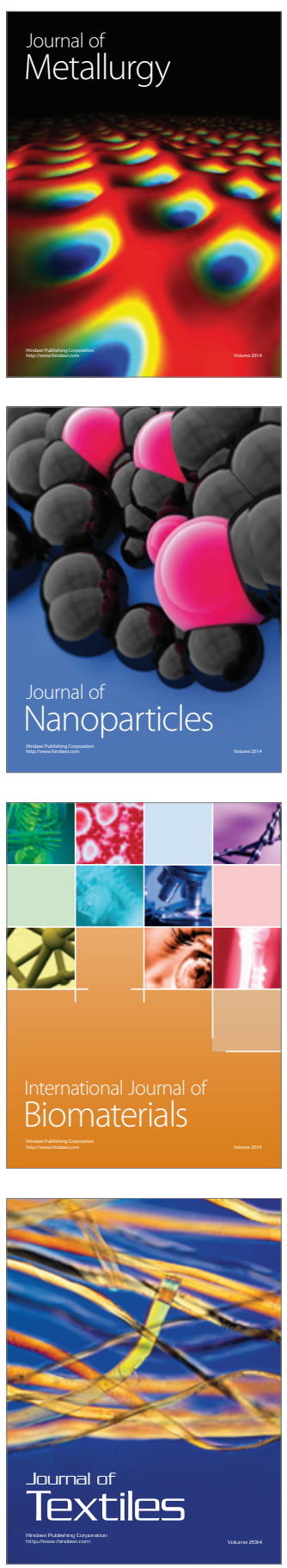